\title{
3 \\ Indigenous life in the Admiralty Islands
}

Direct knowledge of life in the Admiralty Islands before European contact is beyond our grasp. But the works of Fortune and Mead, based on their 1928 research among Titan speakers, describe in great detail major features of life at a relatively early point in the Australian colonial era, and Nevermann (1934) provides a useful compilation of observations from the German colonial era. We also rely in this chapter on what Schwartz learned of the precolonial and early colonial eras from his research in the 1950s. In addition, in the 1960s, to get a wider view of life in the Admiralties, Schwartz circumnavigated Manus Island and travelled the surrounding waters by motorised outrigger canoe to visit scattered Titan and Matankor villages, and he trekked to Usiai villages in the interior. His research confirmed the wider relevance of Mead's, Fortune's, and his own earlier findings on the south coast and in the southerly islands. It also allowed him to understand better how, despite the many things that divided them, the peoples of the Admiralties comprised what he calls an integrated areal culture (Schwartz 1963). We refer to this substantial body of research to illuminate why forging even fragile unity among dozens of villages in the Paliau Movement was a remarkable accomplishment; the circumstances that gave Paliau's call for radical change its appeal; and the aspects of the Admiralties areal culture that contributed to people's susceptibility to the Movement's millenarian aspects.

We first describe the relevant dimensions of precolonial or early colonial life in the Admiralties and the links among them in a couple of paragraphs, before addressing them in more detail. The precolonial Admiralties were 
highly fragmented politically; trust and solidarity were fragile at all levels, from the major ethnic groups down to the nuclear family. Nonetheless, in the quest for leadership and prestige, ambitious individuals built networks through which they amassed goods for the exchanges associated with marriage. As Mead and Schwartz put it (n.d.: 19-20): 'Among any sample of individuals from the same village, there would be no exact correspondence in the range of their allegiances, the areas where they could travel safely, the villages into which they might move, or the quarrels and combats in which they might become involved'. To the extent that lineages, clans, or villages collaborated in a venture, it was because the individuals initiating the proposed ... exchange, trading voyage, or raiding party invoked lineage or clan or village membership as a reason for temporary cooperation'.

What Fortune called Manus 'religion'-more concretely, people's relationship to the ghosts of the dead-reinforced the marriage exchange system by punishing failure to meet trade and exchange obligations and breaches of sexual morality, for the latter endangered the stability of marriages, thus affecting the exchange system and all that it entailed. The role of the ghosts of the dead was the most prominent feature of a prevailing disposition to see the world as governed by conscious forces, vitally interested in human affairs. Here was fertile ground for both the comparatively gradualist millenarian hopes interwoven with the secular efforts of the Paliau Movement and the apocalyptic cargo cult visions that took hold within the Movement. Despite the great cultural similarity of all the peoples of the Admiralties, some villages remained outside the Movement and its cults while apparently similar villages joined enthusiastically. There is no simple explanation for this. It is to a great extent, however, the result of the play of micropolitics described in later chapters. And these micropolitics often reflected the way in which particular locales specialised-beyond the limits imposed by local environments - in producing goods for trade, and the constant struggle of established and would-be leaders to avoid the ignominy of subordination to others.

We begin below a more detailed description of the features sketched above by describing the social fragmentation of the indigenous Admiralties, ranging from the fault line at the heart of the nuclear family to the omnidirectional armed hostility among villages. Yet, as we consider next, the people of the Admiralties were integrated in a dense pattern of interlocking networks centred on individuals seeking leadership and prestige, a quest in which the exchanges of material goods surrounding 
marriage were crucial. The central role of such exchange is important in the story of the Paliau Movement because it became the most obvious focus of young men's discontent as precolonial ways began to lose their hegemony. This despite the punishment household ghosts visited on those who failed to honour the system's requirements. Paliau and others eventually rejected these ghostly enforcers, but—ironically — the ghosts were merely one face of an all-embracing cosmology of animate and personal causation without which there would probably have been no Paliau Movement.

\section{A fragmented social world}

In 1953, Schwartz estimated that the total indigenous population in the Admiralty Islands was about 15,000. The postwar Australian administration, the Australian New Guinea Administrative Unit (ANGAU), also estimated the indigenous population during World War II at about 15,000 (ANGAU 1944). Bogen (n.d.) estimated a total postwar population of 12,500 , divided among about 1,200 Titan in some 10 villages, about 6,500 Usiai in some 70 villages, and about 4,500 Matankor in about 45 villages. The people of each of these three ethnic groups considered themselves distinct in numerous ways from the people of the others and tended to marry within their respective groups. Many Manus people told Schwartz that in the past some people of the Admiralties had practised cannibalism, but - they said-while they married endogamously, their ancestors had eaten only members of other ethnic groups; that is, they had practised exophagy. But none of these three groups acted in concert in other ways, and warfare was as common among people of the same ethnic group as among members of different groups.

Villages varied considerably in size. They were the largest units with any degree of internal cohesion, but this cohesion was loose. Most villages comprised one or more patrilineal clans - that is, families related by descent through men from common male ancestors several generations in the past. A village was usually known by the name of the dominant clan or the name of the village's location. The most prestigious adult male of a clan functioned as its leader. In a multi-clan village, people recognised the most prestigious clan leader as the village leader; as long, that is, as he maintained his prestige. The leaders of some villages were more skilled in trade, exchange, or warfare than the leaders of others, but this did not confer on them any authority over other villages. 


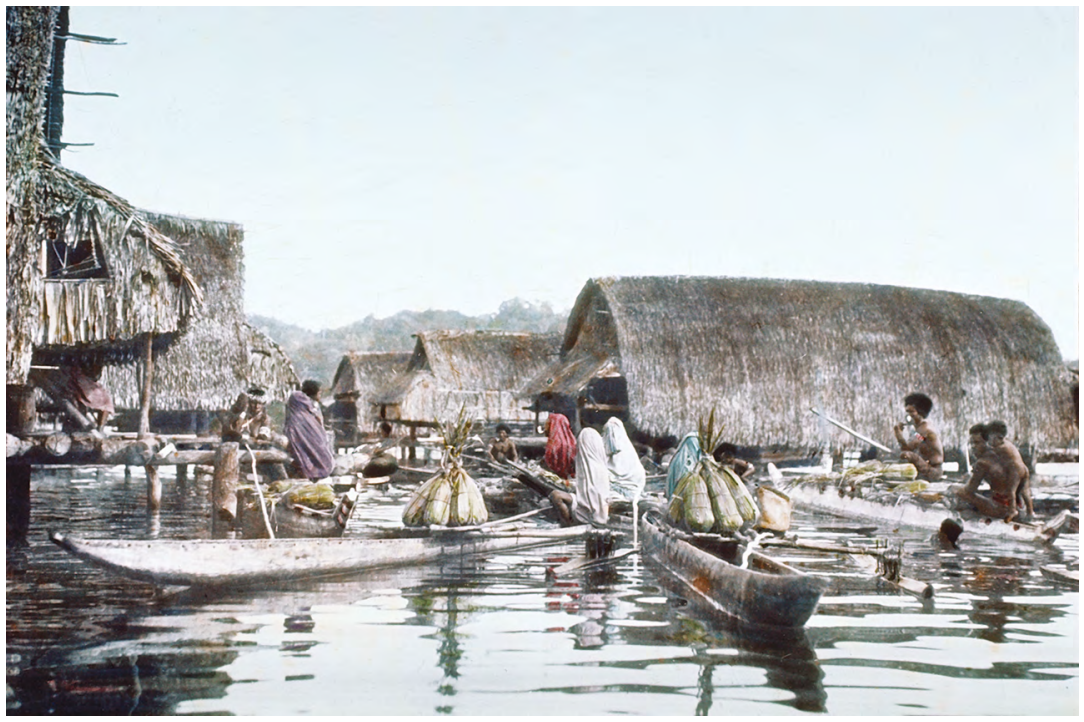

Figure 3.1: In Pere village in 1928, houses and other structures were built on pilings over natural or artificial lagoons. People moved around the village by canoe.

Source: Reo Fortune, from the collection of Theodore Schwartz, now housed in the Archive for Melanesian Anthropology, University of California, San Diego.

Villages with populations diminished by warfare or disease sometimes ceded their autonomy to join more populous villages. Villages and clans, however, were also prone to splitting. Given sufficient strength in numbers, lineages - that is, segments of clans 1 - sometimes claimed recognition as entities distinct from their clans of origin, with their own leaders. Pursuing such a split was the only option for an ambitious man wishing to escape subordination to another: "To have a "name" required that one have a "place" and public of one's own, however small, if one's feats of warfare and exchange were not to redound to the credit of another' (Schwartz 1975: 110). Individuals could increase their own prestige and authority by creating autonomous places, but the overall effect was to dilute the value of leadership by keeping villages from getting very large.

1 More precisely, segments comprising descendants through men of common male ancestors closer to the present than the common clan ancestor, but still some three to six generations above their senior members. 
As we will see below, neither warfare nor ritual institutions fostered unity beyond the clan or the village, which were themselves fragile, schismatic entities. Individuals dispersed among several clans or villages sometimes collaborated in waging war. Warfare 'usually established or involved participation in extended chains of retaliation', but it did not produce 'resolution, cohesion, [or] linkage' (Schwartz 1963: 83). Neither did tending the critical relationships between the living and the dead create even temporary episodes of any wider unity. It was, to the contrary, very much a household affair in which even the interests of husbands and wives could diverge.

\section{Warfare, village vulnerability, and divided households}

Lack of political units larger than the village and the absence of any overarching authority that might mediate disputes between people of different clans or villages provided an ideal environment for chronic armed hostility. Cases that have been recorded suggest that, both within and between the ethnic groups, some fights were about control over locations favourable for trade: for instance, Titan groups competing for control over sea or river routes giving easy access to trade with Usiai; Usiai competing with other Usiai for easy access to the coast, where they could trade with Titan and Matankor; or Titan and Matankor struggling over routes favourable for sea trade. Nevermann (1934) drew from German colonial records evidence of near-constant raiding between the Titan of Mok and Mbukei islands between 1906 and 1910, under the leadership of particularly aggressive war leaders, although he did not comment on the raiders' motives. ${ }^{2}$

Schwartz (1963) describes features of social networks that would have helped avert conflict, but they were at best only moderately effective. A temporary truce prevailed when people from several villages and different ethnic groups met on comparatively neutral ground, such as a beach or a riverbank, to trade products of the sea for products of the land and to barter the various manufactured items in which particular groups specialised. Even so, Admiralties oral history includes accounts

2 We have not been able to locate a page number for this reference. It appears in Schwartz's notes without one. 
of instances in which groups took advantage of such markets to ambush their enemies, willing to disrupt the vital flow of trade to exact revenge for a death suffered or captives taken in a previous encounter. ${ }^{3}$ To a great extent, each village stood on its own.

Some inter-village raiding probably had little to do with trading prerogatives. While in the long run this perpetuated cycles of violence, in the short term it might have made villages more secure by demonstrating their capacity for violence. The preferred weapon for most fighting was a spear, preferably with an obsidian point, used without a shield. Practising spear skills was a common pastime among boys and young men, and their elders occasionally organised raids so that youths could validate their manhood by killing or wounding an enemy. While individual participants gained prestige from a successful action, the greatest prestige accrued to a raid's leader. Men kept count of the number of enemies they had killed by adding to a bundle of sticks; a war leader was also entitled to add a stick for every enemy killed by a member of one of his war parties.

Warfare was not a clear-cut affair of village against village. Like trade and exchange, it was something individuals organised, recruiting participants from among those having obligations-perhaps related to trade or exchange - to the leader and those eager to increase their own prestige. People belonging to a war leader's village or clan who had close kin or trading partners in a group to be attacked could choose not to take part in a particular action. But this was not necessarily without cost. If it appeared that someone had alerted the targets of a raiding party, their kin and associates in trade and exchange would have been obvious targets of suspicion. Many men, of course, were related to people in other villages through their wives, placing them in a delicate position with respect both to war leaders to whom they might have obligations and to their wives. If a man calculated that joining a raid in which he might encounter members of his wife's family was more to his advantage than sitting it out, he still had to try to keep his wife from alerting her kin, or face suspicion, if the raid went awry, that she had done so.

3 Children taken as captives generally would have been adopted; women might have become wives, or they might have been held to serve as prostitutes. Titan people of recent generations have disputed this last assertion, but the accounts that Mead, Fortune, and Schwartz collected from older generations support it. 


\section{Prestige, exchange, and obligation}

Hereditary rank was a feature of all groups in Manus. Some version of a two-rank system appears to have been present in each of the three ethnic groups, as confirmed by Otto (1991: 69), citing Romanucci (1966: 36), and Carrier and Carrier (1989: 69). Titan speakers recognised two hereditary ranks. Persons or lineages of the higher rank were called lapan; those of the lower rank were lau. All members of a lineage shared the same rank. But to maintain a lineage's status as lapan, at least some members in each generation had to act as lapan were expected to act; although one could gain prestige without being lapan. To be lapan meant little if one did not validate the rank through prestige-building endeavours.

As noted above, a man could gain prestige by taking part in or leading successful war parties. But by far the most important route to prestige was success in organising the exchanges of goods central to the marriage system. ${ }^{4}$ Mead (2002 [1934]) and Schwartz (1963) have described the complexities of the relationships formed by marriage in the Admiralties in some detail. For our purposes, it is enough to understand the bare bones. People married outside their lineages. ${ }^{5}$ Such a marriage either created or continued an enduring relationship between the lineage of the groom and the lineage of the bride. A man or woman on the side of the bride (in Titan, lom pein) established by a previous marriage had the right to demand from the side of the groom (in Titan, lom kamal) a daughter in marriage to his or her son. Once a match was agreed-which did not require the consent of the prospective bride and groom-it was formalised by an exchange of goods between the bride's side (lom pein) and groom's side (lom kamal). The groom's side presented to the bride's side durable wealth, which in precolonial and early colonial times would have included dog's teeth, decoratively incised and worked into elaborate body ornaments, and so-called shell money-that is, small shell discs drilled with centre holes and strung on hand-made cord or fashioned into body ornaments. The bride's side presented food to the groom's side. In precolonial or early

4 Otto (1991: 74) confirms that war leadership was also an important source of prestige on Baluan Island. There, too, 'the general picture of the leader as an economic entrepreneur is certainly valid', although 'investment in other people's marriages may not have been prominent' (cf. Carrier and Carrier 1985, 1989).

5 Readers who are not anthropologists need to remember that in a patrilineal system like that of the Titan, a lineage is not a group of men descended through men from a common male ancestor. It is a group of men and women descended through men from a common male ancestor. Both men and women belong to their father's lineage, but only men pass that membership on to their children. A woman's children belong to their father's lineage. 
colonial times, this would have been both cooked food (pigs, taro, yams, sago, and fish, accompanied by coconut oil), on which all those attending the ceremony feasted, and uncooked quantities of the same items that members of the groom's party carried home.

This initial exchange, however, was not enough. To maintain the prestige of the parties and continually validate the marriage and the relationship between lineages it created or maintained, further exchanges of the same kind were necessary at various stages in the marriage and the life cycle of the children resulting from the marriage, including their deaths. One generation, then, might have to carry on a series of exchanges begun by the previous generation. It is better to call these affinal exchanges-that is, exchanges between people related through marriage- than marriage exchanges, because, although begun with marriage, they eventually involved a much wider variety of events. Since members of a single lineage could contract marriages with members of several other lineages-in some providing a husband, in others providing a wife-they could be involved simultaneously, but in different roles, in several affinal exchange series.

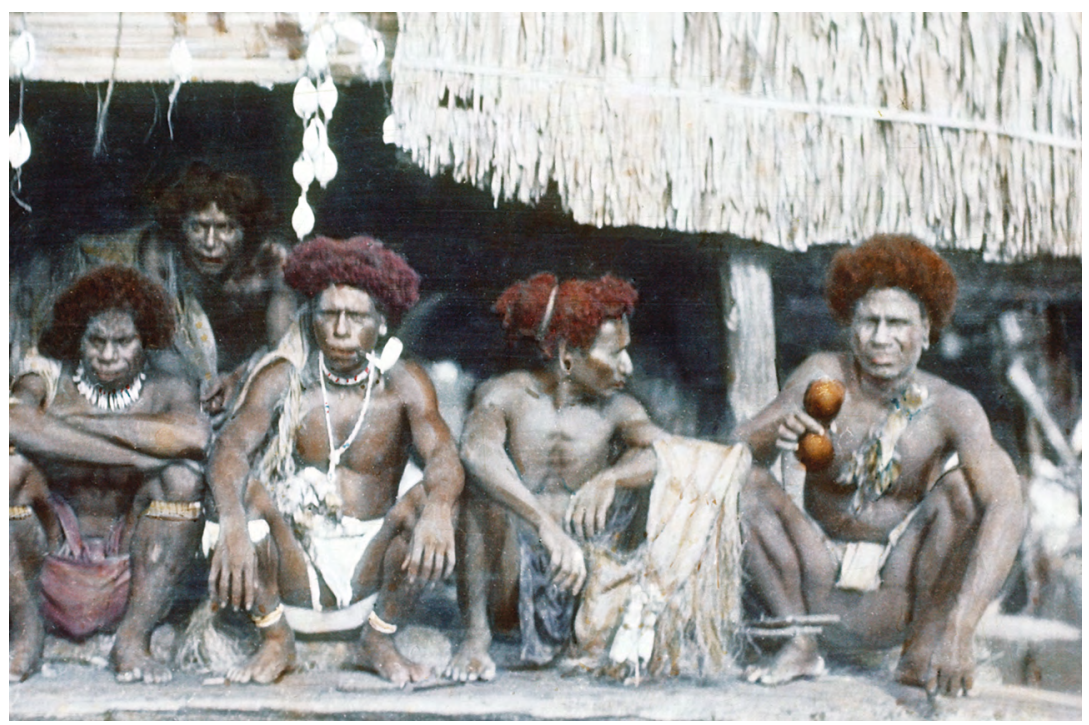

Figure 3.2: Pere village men, photographed in 1928.

They were probably not resting, but planning a prodigious exchange of wealth to seal a marriage and build their social status.

Source: Reo Fortune, from the collection of Theodore Schwartz, now housed in the Archive for Melanesian Anthropology, University of California, San Diego. 
Although both sides in an exchange had firm obligations, greater prestige attached to giving durable wealth, and Titan spoke of the durable wealth given by the groom's side as a payment and of the food given by the bride's side as simply the return. But, although a lineage therefore gained more prestige by carrying out the exchanges entailed by the marriage of one of its young men, his sisters and their descendants were believed to have the power to bless or curse the brothers' children and their descendants by invoking the spirits of the dead-the power of tandritanitani.

It was impossible, however, for a prospective bride or groom or their immediate families to accumulate the wealth needed for even an initial exchange without help. Even all the members of a man's or woman's lineage working together could not muster either the labour power or all the skills and resources to produce the goods needed. Affinal exchange also depended at least as much on trade as on production. Trade took many forms, including barter at markets, where people could chose with whom to exchange their products on each occasion, and established trade partnerships between individuals. The latter were ongoing relationships, sometimes passed from generation to generation, between suppliers of specialised products. Thus, trade partnerships crossed ecological zones and ethnic lines. In contrast to the barter at markets, such trade could be delayed. That is, one partner could supply goods to the other, sometimes in response to a direct request, and not receive the agreed-upon return in goods of another type until much later.

Some specialisation in production depended on having specialised skills or access to particular raw materials. For instance, villages with access to the few locales where one could find obsidian specialised in producing spear points and knives. But specialisation in manufacturing many other items - such as clay pots, carved wooden sleeping platforms, or particular types of baskets-was largely based on a locale's claim to priority and people's recognition of that claim. This kind of arbitrary specialisation would have helped foster networks crossing lineage, clan, village, and ethnic boundaries. But it is unlikely that anyone honoured claims to manufacturing precedence with this result in mind. It is more likely that people simply recognised that the costs of violating such claims outweighed the benefits. Locales probably defended their rights in such matters fiercely. In Papua New Guinea (PNG) today, fierce disputes still erupt between villages or clans over rights to use particular designs for dance regalia or to practise certain kinds of magic. But it is perhaps more fundamental that people recognised that imitation was a losing tactic in 
the constant competition for prestige and distinctive local identity, a point we will return to when we look at the distribution of participation in the Movement and the cargo cults within it.

A man vigorously seeking prestige through playing a central role in numerous affinal exchanges would need many trading partners, involving him in a complicated web of what an accountant would call payables and receivables. A lot of wealth would have passed through his hands, but he would have held none of it for long. He would have poured some into new or ongoing series of affinal exchanges, used some to pay debts to trading partners, and used other goods to put trading partners in debt to him so he could count on the goods owed him for a future affinal exchange.

If a man was active and skilled in the wheeling and dealing required to 'finance', as Mead put it, affinal exchanges, he could do so to obtain spouses for his children. If not, a male kinsman could take on the responsibilityand the potential additional prestige - of arranging their marriages and organising and accumulating the goods, or the promises to provide the goods, for the series of exchanges the marriages would entail over many coming years. Marriage immediately placed both women and men under heavy obligation to those who had organised their unions, committing them to work off their debts by producing and trading for goods that their sponsors could put into other prestige-building exchanges.

The affinal exchange system put great pressure on people to remain married; if a union dissolved, all the networks of payables and receivables focused on the exchanges validating the union were thrown into disarray. But the system did nothing to mitigate men's and women's resentment at being forced into marriages not of their choosing or the resulting tension in the relationship. On the contrary, Mead (2002 [1934]: 61) noted, after marriage, husbands and wives remained bound to those who made the required payments and returns, thus beholden to the opposite sides of tense relationships between larger groups. Even at this intimate level, then, there was a significant barrier to trust and solidarity.

Mead also observed that, once betrothed, the young often resented the elders to whom they now owed years of labour and subservience, and she called the constant production, trade, and close accounting of debts of the affinal exchange system an 'economic treadmill' from which it was virtually impossible to step down (2001 [1956]). Mead described the limited choices a man had within this system: he could remain permanently 
indebted to whomever had financed his marriage, not attempting to free himself from obligation and remaining merely a helper in his sponsor's endeavours; he could work off his initial obligation and then take control of the further exchanges entailed by his marriage, but not attempt to engage in financing the marriages of others; or he could work off his obligation, take control of the further exchanges entailed by his own marriage and work towards becoming a financier of others' marriages.

Gaining prestige on one's own-becoming a man of renown-was the reward for taking the latter course. But once established as a successful financier of affinal exchange a man could not relax. One's prestige lasted only as long as one kept up with ongoing series of exchanges and continued initiating new ones. Even a man who chose to remain subordinate to the sponsor of his marriage had continuing obligations to provide goods for the sponsor's endeavours and even men with very limited ambitions risked loss of their limited status if they did not meet their correspondingly limited obligations. Women were expected to produce and trade for those who had arranged the bride's side of their betrothal, wedding, and subsequent exchanges, as well as for their husband's endeavours. They managed their individual networks of payables and receivables, and their good names depended in significant part on their skill and vigour in producing and trading for goods for exchange.

\section{Ghosts, morality, and exchange}

In addition to the repercussions for one's status, there were powerful supernatural sanctions, applicable to both men and women, for shirking exchange obligations. The constellation of beliefs and practices revolving around men's guardian spirits that Fortune observed among Titan speakers (that Fortune called their religion) had parallels among Usiai and Matankor. The preferred guardian spirit was the ghost of a man's father, whose skull would have been decorated and kept in a wooden bowl stowed securely in the house rafters. Fortune translated the Titan term for this deceased household member, moen palit, loosely but memorably as Sir Ghost. Sir Ghost punished moral lapses of those under his scrutiny. He also was expected to protect household members from misfortunes, such as an accident at sea, and attacks by the Sir Ghosts of other households, which could be motivated by pure malice. Titan attitudes towards Sir Ghosts regarding their responsibilities as protectors 
were severely practical. If a man's Sir Ghost failed to protect members of his household from misfortune and, as was inevitable, death, he replaced him with the ghost—and the skull—of another recently deceased male kinsman. Titan never took death as 'natural', and if they did not regard it as punishment for sin they usually attributed it to the malice of another household's Sir Ghost or to malicious magic, hence the need for a Sir Ghost's protection. Fortune (1965 [1935]: 8) described the fate of a discredited Sir Ghost as follows:

His skull may be battered to powder, and the powder thrown into flames, or it may merely be hurled into the sea. Sir Ghost becomes a vague lurking danger of the middle seas, not very seriously regarded - then a sea slug. But the system goes on. A new skull is bleached from the corpse of the recently dead. It is installed in the house front with the women wailing at the reminder of the death.

The Sir Ghost's role as moral watchdog is more germane to the system of affinal exchange and its relationship to the Paliau Movement than its role as protector. Sir Ghosts could mete out misfortune or illness to household members who violated moral rules or to members of the violator's family not resident in the household. Sir Ghosts were especially concerned with sexual morality and meeting obligations in trade and exchange, but they also found indolence morally offensive. Sexual offences could range from incest or adultery to more subtle but, in the ghost's view, equally dangerous acts, such as bodily immodesty or neglecting to avoid any of the categories of opposite-sex kin with whom an individual was forbidden to have contact. Young men and women, for instance, were forbidden even the most casual contact with their betrothed and men and their mothers-in-law were to avoid each other sedulously. ${ }^{6}$

Confirming that an illness or misfortune was ghostly punishment for immoral behaviour required the services of a diviner or a medium, the former generally a man and the latter generally a woman. Men and women got their powers of detection ultimately from the Sir Ghosts, but they paid established diviners or mediums to be 'consecrated' in their roles, in Fortune's language (1965 [1935]: 29ff.). A major difference between male divination and female communication with the spirit world (relevant to events in the Paliau Movement that we will describe later) was

6 Mead (2002 [1934]: 52ff.) discusses a variety of types of avoidance behaviour, as well as relationships in which joking and familiarity are permitted, that she and Fortune observed among the Titan in 1928. 
the medium's use of a spirit intermediary-often the ghost of her dead child - which announced its presence by whistling (that is, whistling via the medium). ${ }^{7}$

Mead (2001 [1956]: 55) emphasised how these beliefs and practices spurred unremitting attention to trade and exchange:

This system ensured that the rich and enterprising were punished if they paused for a moment in pursuing their far-flung enterprises, and that the man who had elected to remain a dependent of some entrepreneur was chastised for not fulfilling his simple dependent role. The man who had elected to stand aside from the complexities of high finance and simply fish was chastised for not returning some very small debt or for letting his house floor get dilapidated.

Since the people of the Admiralties did not entertain naturalistic explanations for illness and death, they must have found it disturbingly easy to find evidence that they or others were moral laggards.

Mead's portrayal of the burdens imposed on Titan adults by the system of affinal exchange, including the harsh moral regime the ghosts enforced, is so relentlessly dark that one could easily wonder if she was exaggerating or maybe overlooking some dimension of Titan life that softened the rough edges. We have already noted that trade, including arbitrary local specialisations that inhibited local self-sufficiency, would have helped integrate a fragmented social world. Marshall Sahlins (2013) finds more metaphysical significance in the complexities of Admiralties affinal exchange. Drawing on a theme in anthropology with deep roots, he argues that, to the people of many societies, distant strangers who are potentially dangerous are also a source of life-giving power. Hence, affinal exchange was much more than an exhausting and stressful way to organise sexual reproduction or promote industry; it was a way of sustaining 'existence' (p. 285)—not just the social status quo, but being/existence

7 Fortune (1965 [1935]) describes in detail the methods diviners and mediums used to contact, question, and obtain answers from the spirit world; social influences on their findings; and the expiatory payments made, on both the mortal and spirit planes, to produce cures. Women did not enjoy the same degree of protection from a Sir Ghost as men did (ibid.: 25ff.), but their moral lapses could trigger more widespread consequences. As Fortune explains: 'In case of a woman sinning sexually, she and her husband's kin, and also her brother's kin may be punished by the Sir Ghosts of the respective kin ... where[as] sexual sin or other sin by a man is dangerous only to himself and to his own kin, his wife alone among affinal kin being added' (ibid.: 27). 
itself-through transactions with a 'spiritually charged outside' (p. 287). That is, trade for and exchange of 'foreign wealth' (p. 285) revitalised the parties involved on a metaphysical level.

This sounds less grubby and more deeply rewarding than scrambling to keep one's footing on Mead's 'economic treadmill'. But if the people of the Admiralties recognised, even inchoately, this metaphysical significance, it does not appear to have made the system less onerous. According to Fortune (1965 [1935]: 7), many Titan found the strict moral oversight of the household ghosts — an integral part of the system — hard to take, not only because the ghosts punished moral lapses, but also because they subjected people to the shame of public confession. He observed in 1928 that there was talk among the Titan of 'throwing all the ancestral skulls into the sea, thus throwing out all their Sir Ghosts, and adopting instead the Christian God [as represented by the Catholic Mission]. The advantage stated ... is the substitution of private confession and private expiation of sin for public confession, public indictment, and public expiation of sin'. Many Titan did affiliate with the Catholic Mission within a few years of Mead's and Fortune's sojourn with them. The presence of an alternative-Catholicism - undoubtedly helped move people to recognise and articulate their discontent. We will see in Chapter 4 how experience with wage labour and life among white colonials influenced later critics of affinal exchange, including Paliau.

\section{A world of animate and personal causation}

One cannot understand the indigenous world of the Admiralties without recognising the critical role of the household ghosts. But to comprehend some aspects of the Paliau Movement, it is even more important to recognise that the beliefs and practices pertaining to the ghosts are part of something more fundamental: a cultural world in which impersonal natural forces and processes play minor roles at most, and people typically invoke conscious entities - human, alive or dead, and non-human-to explain events, especially unwelcome events. Fortune emphasises that, in 1928, Titan assumed that ghosts were not only capable of causing illness and death, they were virtually the only cause: 'there is no secular attitude towards the life and death of the body or towards the body's ills. Death is regarded as punishment of sin. It is not accepted as impersonal' (Fortune 1965 [1935]: 8). Neither was serious misfortune of other kinds 
accepted as impersonal. In a world governed by entities with humanlike motives and emotions, events of human significance could not be accidents. ${ }^{8}$

There are people everywhere prone to personifying the forces and processes that shape life, but such a view is not dominant everywhere. Its significance in a particular society may be most obvious in how people understand disease. In their classic volume Medical Anthropology, George M. Foster and Barbara Gallatin Anderson (1978: 54) distinguish naturalistic from what they call personalistic explanations of illness. They emphasise that personalistic is not a synonym for supernatural. Personal causes, for instance, may include human witches and sorcerers who might 'draw on the supernatural', but they are human. Foster and Anderson (1978: 56) also emphasise that a naturalistic approach to medicine is not necessarily a mainstream, contemporary Western approach, citing as examples humoral pathology, Ayurvedic medicine, and traditional Chinese medicine.

Foster and Anderson also observe that people in a given society may resort to both personalistic and naturalistic explanations of disease, the type of affliction often determining the type of diagnosis and treatment deemed appropriate. ${ }^{9}$ A personalistic or personifying understanding of disease, however, is still strikingly dominant in rural PNG and would have been considerably more so before the introduction of Western naturalistic medicine.

Many anthropological studies of Melanesian peoples build on the thought of Marcel Mauss, as expounded in his 1925 volume The Gift: Forms and Functions of Exchange in Archaic Societies. Mauss argues that where gift exchange predominates, people construe the things exchanged, particularly on ceremonial or ritual occasions (e.g. in affinal exchange

8 We have already introduced Schwartz's other name for this cultural construction of the world: a cosmology of animate and personal causation. Since it pertains to fundamental ideas about the nature of being, one might want to call it an ontology. But, without losing anything, we could also speak of this conception of things as a type of world view; a phenomenological ecology, to use a term Schwartz also favours (1991: 185-6); a type of behavioural environment, following Hallowell (1955); or an aspect of what Pierre Bourdieu calls habitus (1977). There are many acceptable options. We will, however, stick with cosmology to remain consistent with Schwartz's earlier work.

9 When people distinguish general categories of diagnosis and treatment that mirror the naturalistic-personalistic divide, they do not necessarily understand the distinction in these terms. In rural PNG, for instance, people often distinguish afflictions that can be treated with European medicine from those requiring indigenous methods, that is, methods based on personalistic understanding of disease. But we have never heard rural Papua New Guineans speak of such specific distinctions in terms of broad abstractions. 
in the Admiralties), as parts of persons or as partaking of the substance of the giver. More recently, Marilyn Strathern (1988: 178) writes of exchange in Melanesia that 'things are conceptualised as parts of persons ... They are not, of course, apprehended as standing for persons: that is our [i.e. an outside observer's] construction'. ${ }^{10}$ Writing of the Gimi people of highlands PNG, Paige West (2016: 93) affirms that in societies based on gift exchange, 'identity and personhood are made through social relationships with others'. Further, these are relationships of 'exchange and transaction', and the Gimi see themselves as having social relations with 'animals, plants, people, and spirits' (ibid.: 98). The result, as West conveys vividly (without, however, using our terminology), is a deeply personified world. She explains that the Gimi call 'the force that animates a living person' auna, and continues:

When a person dies, her auna leaves her body and migrates to the forest. Once there, the auna slowly turns into kore ('ghost', 'spirit', 'ancestor', and 'wild') and lodges in plants, animals, streams, mountains, birds, and other bits of what we call forests. The life force of a person becomes the forest, with the 'wild' parts of the forest becoming filled with and 'animated by' the kore of the deceased Gimi. Once the auna goes to the forests and begins to infuse itself into wildlife, it becomes part of not only the forest but also the never-ending cycle of Gimi existence. (West 2016: 93)

When a hunter kills and eats a marsupial, 'The [marsupial] as food makes the hunter's body while the [marsupial] as embodied ancestor or kore makes the auna of the hunter' (West 2016: 95). ${ }^{11}$

\section{The dark side of a personified world}

It is easy to find the dark side of personification in Fortune's description of the role of household ghosts in Titan life. Fortune's and Mead's view of Titan life in general in 1928 teeters on the edge of negative romanticism. West's depiction of the Gimi world teeters on the edge of positive

10 Marilyn Strathern's The Gender of the Gift (1988) explores the implications for anthropology of this theme in Mauss in Melanesia and beyond, with special emphasis on its implications for understanding gender. Her work has become a taken-for-granted starting point for much current research. In discussing Schwartz's work on trade and exchange in the Admiralties, Sahlins (2013: 284), for example, speaks of the 'inalienable person-attributes of the things exchanged'.

11 The type of marsupial West uses in this example is known as a kile in the Gimi language and in Latin as Macropodidae Dedolagus goodfellow (West 2016: 95). 
romanticism. But even in such positive romanticisation there are hints of the dark side of personification, an important topic for understanding aspects of the Paliau phenomenon. ${ }^{12}$

West describes the social relations that make up the Gimi world as 'familial and poetic' (2016: 93). And the Gimi world as she describes it sounds like one in which people would be untroubled by the anxiety regarding salvation Christianity generates, the deep unease of life in a modern world the inhabitants of which suspect has no inherent meaning, or the existentialist vertigo of confronting one's freedom from the past and responsibility for the future. To the Gimi, 'everything that "is" and that ever will be is the physical incarnation of their ancestors' life force' (West 2016: 93), a perception we can imagine would make one feel profoundly at home. ${ }^{13}$

But it might not necessarily make one feel profoundly at ease. Life in a deeply personified world is not necessarily more humane than life in a world shaped by naturalistic assumptions. As Stephen Leavitt's work (2004: 183-4) illustrates, a world in which one is defined by one's exchange relations with others has characteristic rough edges. Leavitt's research among the Bumbita people of East Sepik Province of PNG convinced him that, despite the intricate web of relationships comprising Bumbita society, people sometimes longed for personal autonomy in a way that rootless, self-reliant (or aspiring to be so) Westerners would find familiar. But for the Bumbita this creates tension with 'an overwhelming sense that one is in fact defined by one's relations with others', and 'that for each action one must consider a myriad of factors relating to one's relatives and associates'. He concluded that many Bumbita find this dilemma 'a severe burden'. Leavitt worked among the Bumbita in 1984-86, when they had been exposed to deracinated Europeans for some time, so it is hard to say if precolonial Bumbita felt a similar conflict, but—as we shall see-young men of Paliau's generation in the Admiralties would have recognised it. ${ }^{14}$

12 West's work on the whole is not as unremittingly romantic as our selections might suggest. Her focus is on the grittier issues surrounding Gimi self-determination in the face of powerful external forces eroding their sovereignty.

13 It is not clear why West encloses the word 'is' in quotation marks.

14 Leavitt (2004: 183-4) also observes: 'Social conditions like these [i.e. those he found among the Bumbita] prevail in face-to-face societies [i.e. small-scale societies, where everyone knows everyone else] everywhere. In Melanesia though, researchers have sought to establish the "sociocentric" bases of self-understandings without asking much about what this means for individuals trying to live their lives on a day-to-day basis'. Day-to-day living in such social conditions, he contends, 'can seem oppressive to individual actors'. 
In addition to the burden Leavitt observed, personification is also associated with chronic suspicion and mistrust. Stanley Diamond (1974: 94) wrote that the intense personal interaction characteristic of small-scale societies often produces not only 'sophistication and subtlety' about people, it also fosters 'dangerous sensitivity'. He was speaking in part of how personification can breed mistrust, begat by the assumption that when bad things happen, other people are generally to blame. Fortune's Manus Religion (1965 [1935]) provides a surfeit of illustrations of this in his detailed cases of diviners and mediums seeking the causes of illness, death, and misfortune (cf. Foster and Anderson 1978: 55). Similarly, Hallowell (1955: 145) writes of the attitude of the Ojibwa of northeastern North America in early colonial times, 'if something goes wrong, it is somebody's fault'.

Throughout the world, where personification dominates, what Schwartz and Smith and their ilk would construe as accidents engender recriminations. West (2016: 97) shows this principle at work among the Gimi, when she explains how a Gimi man understood why his daughter was killed by a falling tree. Since the daughter had been in a part of the forest associated with the kore of her ancestors, she should have been safe; therefore, her father concluded, sorcery-the intentional use of malicious magic - must have killed her. This diagnosis is incidental to West's main point, so she doesn't elaborate on its implications. In PNG, however, a diagnosis of sorcery can be like a match set to dry brush. Such a personified explanation can cast a pall of fear over a community's everyday life, starting — or reviving - generations of hostility within or between communities, and inciting retaliatory violence to the point of torture and murder.

\section{Explaining rampant personification}

We will not linger on some proposed ways of explaining the human tendency to personify the world, other than to strengthen the point that although it is a nearly universal human tendency, the fact that it is stronger in some societies and social contexts than others is subject to explanation. It is not, as Rappaport (1999: 1-2) contends (rather carelessly) of religion, 'indispensable to the species'. And although many members of our species find it impossible to see the world otherwise, we have the potential to make other choices. Only large-scale social and cultural change is likely 
to deprive this tendency of its strength. Banerjee and Bloom (2014: 299), however, provide a hopeful note. Regarding the human propensity for teleological reasoning, they argue that 'although teleological beliefs about life events and nature may be highly intuitive and automatically generated, they can be explicitly overridden by engaging in reflective thought and by inhibiting default causal explanations'.

A number of scholars discuss a human tendency to personify causation as a product of cognitive evolution and a vital element in the general human receptivity to religious concepts. For instance, the work of scholars like Scott Atran (2002) and Pascal Boyer (2001) builds on the work of Stewart Guthrie (1993) to elaborate the hypothesis that evolution equipped human beings with a hyperactive tendency to detect agency in their environments. Hence, as ably summarised by Justin L. Barrett (2000: 31): 'people have a bias towards detecting human-like agency in their environment that might not actually exist. Thus, people are particularly sensitive to the presence of intentional action as the cause of a given state of affairs when data is [sic] ambiguous or sketchy ... such a biased perceptual device would have been quite adaptive in our evolutionary past, for the consequences of failing to detect an agent are potentially much graver than mistakenly detecting an agent that is not there'. Boyer (2001: 33) emphasises that this line of reasoning is not an effort to identify a 'historical origin of religion in the sense of a point in time ... when people created religion where there was none'. Rather, the point is to get at the possible evolutionary roots of a cognitive bias that has been culturally elaborated in many ways, such that it is part of our constant, everyday humdrum cognitive functioning that we interpret all sorts of cues in the environment, not just events but the way things are, as the result of some agents' actions' (p. 145). Daniel C. Dennett (2006: 109) draws on an evolutionary perspective when elaborating what he calls a tendency to adopt 'the intentional stance' and commenting on the human 'disposition to attribute agency' (p. 114). ${ }^{15}$ Bruce M. Hood focuses on ontogeny rather than phylogeny. He hypothesises that what he regards (probably prematurely) as the inevitability of 'supernatural belief' (Hood 2009: xvii) and the difficulty human beings have handling 'the possibility that things happen randomly by chance' (p. 11) are natural products of individual human cognitive development.

15 For a more recent examination of research on human cognitive bias and religion see Van Leeuwen and van Elk (2019). 
None of the above, of course, explains why a universal tendency to personify is more highly developed in some contexts than in others. Schwartz (1976a, 1978b; cf. Smith 1994: 44-69) has proposed the relevance of social scale to the strength of personification in different cultural worlds. An important point in his argument (greatly simplified here) is that small-scale societies provide social environments more consistent with a personifying view than do large-scale societies. In smallscale societies, what Schwartz calls face-to-face ratios are low, perhaps as low as one-to-one if everyone is known relatively equally to everyone else. Hence, the interpersonal ramifications of people's actions are relatively direct and obvious. This is consistent with (Schwartz does not argue for causation) assuming that conscious agents who are intimate with the details of people's lives are among the world's prime movers. To use Peter Berger's (1967) language, life in a society in which all or nearly all are known to each other provides a strong 'plausibility structure' for personification, especially where there is no strong tradition of naturalistic explanation. In contrast, the comparative anonymity of life in large-scale societies can foster the perception that one is unknown (and probably wildly unimportant) to powerful distant institutions. Such a perception is consistent with assigning impersonal causality a central role in events and accepting the importance of specific natural forces, such as gravity, natural selection, weather systems and tectonic shifts, and a social world in which the chance confluence of unrelated events can have effects that neither human actors nor other-than-human entities intended .

Nonetheless, even in large-scale societies that depend on technology that is the fruit of naturalistic understanding of the world, and in which anonymity is not only possible but common, people continue to indulge in teleological thinking and invoke supernatural entities and metaphysical forces to explain things. A prime example: even as more and more of the world's people become entangled in global social networks and depend on complex digital technologies, theism thrives. As Schwartz (1978b: 225) writes, 'The notion of an omnipresent, omniscient god, aware of and concerned with the detailed behaviour of each person, is obviously a small-scale concept extended to the most extreme asymmetrical face-toface ratio', that of all of humanity to a single deity. But this is something to be explained, not evidence of the inevitable nature of things. 
It is apparent that-as noted in Chapter 1-the conspicuously dark form of personification that Barkun (2006 [2003]) calls conspiracism is gaining strength in the world at large, including the technologically highly developed West. We return to this topic in Chapter 15, our final chapter.

Personification is a critical concept in our discussion of the Paliau Movement. Paliau grounded all his efforts to revolutionise indigenous society at least in part in a cosmology of animate and personal causation entirely in keeping with indigenous orientations. That Paliau's cosmology drew extensively on a personifying European mythology-mission Christianity-gave his vision greater weight as the basis for a plan to attain parity with the Europeans. To be complete, any explanation or interpretation of Melanesian cargo cults must acknowledge that the prevailing personifying orientation is something to be explained as well as part of the explanation. ${ }^{16}$ The dark side of personification is especially relevant to the mixture of credulity and suspicion characteristic of cargo cults at their peaks.

\section{Personification and pragmatism in indigenous Manus}

Emphasising the ubiquity of a personifying tendency in our species should make cargo cults look less like an especially exotic kind of otherness and more like people doing something familiar-millenarianism-in a historically and culturally distinctive way. It is also important to keep personification in the forefront because the sphere in which naturalistic views are not only accepted but valued in PNG (for instance, consider the growing number of indigenous medical professionals) is expanding even as millenarianism remains common. It is hard to appreciate the full significance of this if we relegate personification to the background.

Yet despite the densely personified world of indigenous Admiralty Islanders - the strength of a cosmology of animate and personal causation-a number of observers have commented on the high value people of the Admiralties have placed on empirical evidence. Both Mead and Fortune observed that Titan adults had enormous respect for accuracy

16 Nor are explanations of most instances of apocalyptic millenarianism in the West complete without considering the strength of personification in Western societies. 
in describing the physical world, Fortune (1965 [1935]: xi) noting that 'the Manus [i.e. the Titan] delight in facts and argument ... They debate questions about entirely useless matters for the love of truth'. One of Mead's favourite anecdotes was of a Titan man who carried the jawbone of a fish with him for several days so that he could show it to someone with whom he'd argued about the number of teeth the type of fish in question had. ${ }^{17}$

In 1928, the Titan often sought the reasons for troubling events by communicating with the dead, but Mead and Fortune saw Titan adults reject the findings of seances, even though this risked arousing the anger of the ghosts (Mead 2001 [1930]: 90; Mead 2001 [1956]: 95-6). Fortune (1965 [1935]: 2) argued that people rejected the findings of a medium or 'oracle' not simply because they did not like them, but because they thought the medium had not given 'a judgment derived from the will of the [ghost], but rather one derived from the oracle's too clearly human capacity'.

We must recognise, however, that to strengthen the case for Titan practicality, Mead played down some contrasting aspects of Titan life. In Growing Up in New Guinea she described Titan culture in 1928 as not only sober and pragmatic, but also poor in fantasy. That was probably a step too far. Schwartz points out that Titan people showed considerable capacity for fantasy in the same seances that provided Fortune and Mead with evidence of Titan pragmatism. Indeed, one could regard the mediums through whom people communicated with ghosts as specialists in elaborating culturally provided fantasy, in unwitting collaboration with the audience. (This does not, of course, conflict with the idea that on occasion some members of the audience withdrew their collaboration for pragmatic reasons.)

Mead also wrote that the Titan language was 'rigorously matter-of-fact where ours [i.e. American English] is filled with imagery and metaphor' (Mead 2001 [1930]: 95). Schwartz, who has much greater command of the Titan language than Mead had, also observes that everyday speech is relatively nonfigurative. But Schwartz has observed that Titan commemorative ballads, a form of language use different from all others in Manus life, make considerable use of imaginative language. They

17 Fortune (1965 [1935]: xi) employs the same anecdote. We do not know with whom-Mead or Fortune-it originated. 
employ a vocabulary not used in ordinary speech, many words are archaic or foreign, and even common words are pronounced in distinctive ways. Granted, when in need of a ballad to express sorrow or feelings for the dead, those who cannot do it themselves go to a specialist-a man or woman who can invest language with the required emotional richness. ${ }^{18}$

Fortune and Mead, however, made a good case for Titan pragmatism even without such questionable claims. Regarding other Admiralty Islands people, Otto observed similar respect for visible evidence on Baluan Island and presents what he calls a Baluan 'hierarchy of the reliability of knowledge' as follows: 'the highest status belongs to those things you have seen with your own eyes; in second place comes knowledge you have seen the effects of, whether that knowledge comes from dreams, divination or from other human beings; a much lower status is attributed to those things you have only heard about' (Otto 1992c: 437). Similarly, Anders Emil Rasmussen (2013: 104) observes that Mbukei Islanders place high value on 'visible proof' in assessing the reliability of knowledge. The point here is not that Admiralty Islanders value visible evidence more than other Melanesians. ${ }^{19}$ It is to help show how far those who participated in the cults had to depart from their quotidian orientations.

\section{A paranoid ethos}

It is difficult to understand the apparent ease with which Manus people involved in cargo cults dropped their usual empirical orientation without recognising an aspect of indigenous Manus life that pulled against

18 The ballad form seems to have derived its style from the pattern of speech in formal kinship avoidance behaviour. Among relatives such as cross-cousins, between whom obscene joking was expected, the joking was direct, raw, literal, and vulgar. This was potentially dangerous, but it was considered safe as long as it was clearly labelled as joking. For relatives in an avoidance relationship, one had to use oblique reference, never mentioning anything that could be seen as identifying that person directly. This taboo on direct reference was extended to all of the deceased.

19 The literature undoubtedly provides many examples of indigenous empiricism elsewhere in Melanesia. We offer only one. Smith (1994: 78) notes that despite the great importance of spirits of the dead in the lives of Kragur villagers in the 1970s, at least one man found it hard to accept prevailing views or to sympathise with common fears. He was blind and often walked around the village and its environs at night, as confident of the paths then as during the day. He told Smith: 'I never hear a ghost. Nothing makes a noise in the bush or touches me. During the rains when the nights are completely dark everyone says, "Oh, now is the time the ghosts walk around". But I ... don't meet anything'. 
empiricism and pragmatism even in normal times. Schwartz calls this a paranoid ethos. As we will emphasise below, this is not something unique to Manus or Melanesia, but it is vital to understanding the Manus case.

Gregory Bateson introduced the useful concept of ethos in Naven, a study of a ritual he observed among the Iatmul, a Sepik River people, in the late 1920s and early 1930s. ${ }^{20} \mathrm{He}$ defined ethos as 'a culturally standardised system of organisation of the instincts and emotions' (1958 [1936]: 118-19). George De Vos (1976: 9) also offers a helpful phrasing of the concept: 'The ethos of a culture is the characteristic spirit or prevalent tone or sentiment of a people, institution, or system'. Although an ethos develops in relationship to the history and particular circumstances of a population or institution, it can linger as circumstances change: 'In situations of change, patternings in the emotional tone or implicit feelings underlying behaviour may persist in spite of revision in ... behavioural forms' (ibid.). Schwartz (1973) argues that an important element in the typical indigenous Melanesian ethos was a tendency to see and feel the world as a place of ubiquitous danger, requiring constant vigilance, and fostering suspicion of personally relevant meaning beneath the surface of events. Such an ethos militated against entertaining the possibility of chance or coincidence.

Schwartz summarises as follows the conditions conducive to a paranoid ethos in indigenous Melanesia:

The paranoid ethos in Melanesia derived from the uncertainty of life, from the high mortality rate and short life span, from the many births and few surviving children. It depended on the uncertainty of the yield of productive activities even though the technologies were ingeniously diversified ... Perhaps more fundamentally for Melanesia, the paranoid ethos related to the extreme atomism of social and political life, to the constancy and omnidirectionality of war and raiding, to the uncertainty of all alliances, and even to the uncertainty of village and clan cohesion. Uncertainty was experienced as a pervasive threat in terms of the premises of a cosmology of animate and personal causation. (Schwartz 1973: 155)

20 Bateson later became Mead's third husband, after Reo Fortune. But he did much of the research on which Naven is based before he encountered Mead and Fortune, who at the time were also engaged in research among Sepik River peoples. 
It is easy to see how a chronic feeling that 'malice is ... almost omnipresent beyond the narrow circles of relative trust', as Schwartz (1973: 157) describes the dark side of a paranoid ethos, could thrive in such an environment. Our description above of the nature of indigenous social life in Manus illustrates just how narrow those circles of relative trust could be, frequently not even embracing partners in marriage. And the indigenous Manus personification of the world exacerbated perceptions of the dangers of the natural and social worlds, in which objective risks to life and limb were already numerous. If every misfortune is caused by some conscious, but usually hidden agent - if nothing is accidentalthen each misfortune is evidence of lurking malice.

Schwartz is not the only anthropologist to observe a similar orientation among particular Melanesian peoples. Most of Fortune's Sorcerers of Dobu (1932), reporting on his research among the people of Dobu Island, located in what is now PNG's Milne Bay Province-which he conducted prior to his 1928 research in Manus-is devoted to describing a social context that fosters an attitude that could have been crafted especially to illustrate a paranoid ethos. ${ }^{21}$ We must be somewhat wary, however, of relying on this famous work for validation. It was Ruth Benedict, not Fortune, who used the term 'paranoid' to describe aspects of Dobuan life in her 1934 work Patterns of Culture, and Fortune is said to have objected to this characterisation (Antrosio 2013). Decades later, anthropologist Susanne Kuehling (2005) also saw Dobuan life differently from Fortune. ${ }^{22}$

But we do not have to rest on Fortune, or Benedict's interpretation of Fortune. A.L. Epstein (2000-2001) examines his data on the Tolai people of what is now PNG's East New Britain Province to assess the applicability to the Tolai case of Schwartz's conception of a paranoid ethos in Melanesia. Epstein (2000-2001: 17) concludes that his data give 'full support' to Schwartz's thesis. Specifically, he notes a 'pervasive sense of threat and vulnerability ... characteristic of the response of the Tolai to so many aspects of their world' (p. 6), and reports that 'in so many ways ... the

21 Schwartz (1976a: 198) summarises a key element of the Dobu social context as follows: 'The structure of trust and distrust, so important to the paranoid ethos, may have had one basis in the experience of the divided family. The dichotomy of owner and stranger found throughout Melanesia was exacerbated in a matrilineal context, such as that described by Fortune in Dobu ... distrust was intensified by a pattern of alternating residence and alternating roles of owner and stranger between the husband's and the wife's villages'.

22 Antrosio (2013), however, has suggested that in her criticism of Fortune, Kuehling may not have given sufficient weight to changes in Dobuan life in the intervening decades. One should not, however, opt for Fortune's interpretation before reading Kuehling as well. 
[Tolai] world appears [that is, it appears to the Tolai] ... threatening and full of menace', replete with 'enemies in human or spirit form who seek to destroy one' (p. 9). Further, 'the Tolai language does have a word for accident, but I don't recall ever hearing it used to explain some misfortune one had suffered' (p. 11). Among the underlying factors he lists are belief in a panoply of 'generally malevolent spirit beings' (pp. 7-8), chronic 'jealousy over land' (p. 8) and 'elements of the Tolai scheme of domestic relations' (p. 16).

Maria Lepowsky (2011) is uncomfortable with Schwartz's use of the term 'paranoid' and the sweep of his claims, but she finds that the people of Vanatinai Island (also known as Sudest Island) in Milne Bay Province also experience the world as though under the sway of a paranoid ethos. She writes: 'While I would not agree that a paranoid cognitive orientation distinguishes all the cultures of the Southwest Pacific, and although the term bears distinctly unfortunate connotations of individual and societal pathology, I do recognise elements of a similar worldview and affective tone in Vanatinai people's powerful fears of the destructive agency of other persons, particularly other-than-human persons' (2011: 52). And, like Epstein, she emphasises the force of a personifying, chance-rejecting understanding of the causes of misfortune: 'The islanders believe firmly in the personal causation of misfortune. Virtually all deaths, serious illnesses, or misfortunes are attributed to the sorcery or witchcraft of another, or to the retributive acts of ancestors' spirits or place spirits, the result of the victim or a kinsperson having violated a taboo ... a sacred proscription' (Lepowsky 2011: 46). ${ }^{23}$

Rejecting chance is probably a more important dimension of a paranoid ethos for understanding the cargo cults within the Paliau Movement than is the feeling that 'malice is ... almost omnipresent beyond the narrow

23 Lepowsky is not alone in her concern that mention of paranoia 'bears distinctly unfortunate connotations of individual and societal pathology'. Epstein (2000-2001) addresses this issue at the outset in considering the relevance of a 'paranoid ethos' to the Tolai case, concluding that the term as Schwartz and others (e.g. Richard Hofstadter 2008 [1965]) have used it in social analysis is analytically fruitful. Lindstrom (1993a: 70), in service of his own argument, over-interprets Schwartz's own remark (1973: 156) that applying the term paranoid to Melanesian culture may entail 'something more than analogy'. To pursue this issue further, readers should consult Schwartz (1973), Epstein (2000-2001), the literature to which they refer, and Barkun (2006 [2003]: 8), who explores the relationship between Hofstadter's concept of a 'paranoid style', conspiracy thinking, and millenarianism, a topic we will also discuss in Chapter 15. (Hofstadter first aired his thoughts on 'the paranoid style in American politics' in a lecture at Oxford University in 1963 and Harper's Magazine published a shorter version in 1964. His longer essay has subsequently been published in a number of editions, most recently in 2008 [1965]). 
circles of relative trust' (Schwartz 1973: 157). Regarding the Melanesian paranoid ethos, Schwartz (1973: 164) observed: 'There is an attitude towards events and language that rejects coincidence, radically rejects homonymy, and cannot accept rhyme as semantically irrelevant, so that words that sound the same or just similar must have some common meaning'. The strength of a paranoid ethos, then, helps explain Manus people's susceptibility —in their postwar situation — to abandoning their quotidian empirical and pragmatic bent and believing almost anything from almost any source. Those most drawn to the cults, Schwartz observed, simultaneously viewed the world with suspicion-nothing was as it seemed-and were prone to accept reports of events-such as ancestral ghosts piloting American cargo vessels-that they should have found suspect. 'Suspicion and cognitive rejection', observed Schwartz, were 'joined with extreme credulity' (1973: 157).

It takes more than a paranoid ethos, of course, to move people to millenarian fervour. But once it has taken hold, a paranoid ethos knows few bounds. Millenarian fervour virtually everywhere, Landes (2011) repeatedly reminds his readers, is marked by 'semiotic arousal'-that is, rejecting mundane meaning in favour of perceiving signs and wonders.

It is important here to emphasise that when he argued that a paranoid ethos was characteristic of Melanesia, Schwartz was careful to state that some degree of paranoid perspective was probably universally human. It is certainly easy to find examples in the ethnographic literature. Hallowell (1955: 147) linked what he saw as an Ojibwa tendency to assume that 'covert malevolence is always potentially present in one's dealings with others' to rejecting chance- 'impersonal forces are never the causes of events' (p. 181)—and 'social atomism' (p. 147).

A paranoid ethos is not confined to small-scale, non-industrial societies. Regarding the enhanced perception of personal reference that is part of a paranoid ethos, Schwartz has argued that a perception 'of being the centre of malign or benign attention is natural to small-scale societies', but that it 'persists, just as village-size spheres of personal interaction persist, in large-scale societies' (Schwartz 1973: 169; cf. Schwartz 1972). Further, it is part of the common human heritage: 'It persists over the span of human history as a substratum of potential pathology in all societies' (1973: 168). A potential pathology because, taken to extremes, a paranoid ethos can impair a group's capacity to adapt and survive. 
Although an ethos can have great endurance, even as the circumstances that formed it change, Schwartz opined in 1973 that the Melanesian paranoid ethos was changing: 'Many Melanesians have been able to attain a recalibration of expectations more realistic than that of the cults and are now capable of a more relaxed synthesis and selection of cultural features derived from both native and European sources ... alternative modes of personal and group psycho-cultural adjustment are being opened up. For the Melanesian, the paranoid ethos is no longer without alternative' (1973: 172). Yet it remains a significant element in the millenarian dreams simmering today in Wind Nation, as discussed in Chapter 14, even though Manus people today live in a considerably changed social environment.

Now, however, we return to former times in the Admiralty Islands, how Manus people were drawn ever more deeply into a new world from earliest European contacts through involvement in two world wars, and how change coming from outside helped unleash internal demands for change. 
This text is taken from Like Fire: The Paliau Movement and Millenarianism in Melanesia, by Theodore Schwartz and Michael French Smith, published 2021 by ANU Press, The Australian National University, Canberra, Australia.

doi.org/10.22459/LF.2021.03 